\title{
Accuracy of Photorefraction and Wavefront-Based Autorefraction in Children Under 3 Years of Age
}

\author{
Caner Kara, (이 Ikbal Seza Petricli
}

Department of Ophthalmology, Etlik Zübeyde Hanım Women's Health Training and Research Hospital, Ankara, Turkey

\begin{abstract}
Objectives: This study was designed to assess the accuracy of photorefraction and wavefront-based autorefraction in children under 3 years of age.

Methods: A cross-sectional study was performed with children who had no ocular abnormalities other than a refractive error and were less than 3 years old. Spot Vision Screener (Welch Allyn Inc., Skaneateles Falls, NY, USA) was used for photorefraction and SureSight Vision Screener (Welch Allyn, Skaneateles Falls, NY) was used for autorefraction. The measurements were performed with both devices before and after cycloplegia. The results were compared with those obtained using cycloplegic retinoscopy. The assessments were performed in terms of spherical equivalent (SE) values and Jackson cross-cylinder power values (J0 and J45).

Results: A total of 305 children with a mean age of $15.1 \pm 10.4$ months were included. The mean SE values measured with the Spot Vision and SureSight before cycloplegia were $0.43 \pm 0.75 \mathrm{D}$ and $0.90 \pm 0.86 \mathrm{D}$, respectively. Following cyclo-

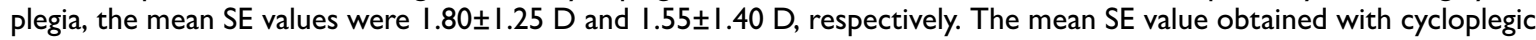

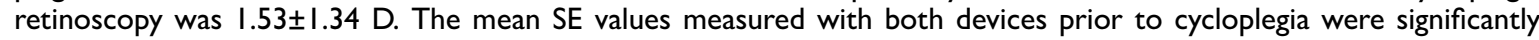
lower than that measured with cycloplegic retinoscopy $(p<0.00 \mathrm{I})$. No significant difference was observed between the cycloplegic SE values obtained with SureSight and retinoscopy $(p=0.66)$. Spot Vision yielded significantly higher cycloplegic SE values compared with cycloplegic retinoscopy $(p<0.00 \mathrm{I})$.

Conclusion: Both devices underestimated SE values in comparison with cycloplegic retinoscopy in children under 3 years of age. Wavefront-based autorefraction performed with cycloplegia may be an alternative to cycloplegic retinoscopy, but needs confirmation.
\end{abstract}

Keywords: Accuracy, amblyopia, child, ocular, refraction, refractive errors, refractometry

\section{Introduction}

Amblyopia is the most common cause of preventable visual impairment in children and young adults, with a reported prevalence that ranges between $2 \%$ and $5 \%(I)$. The earlier the diagnosis and intervention are performed, the better the outcomes (2).

High refractive errors are one of the main causes of ambly- opia (3). The gold standard to determine refractive errors in childhood is cycloplegic retinoscopy. However, the technique has disadvantages in that it requires a certain level of experience, it requires the child's cooperation, it is a time-consuming procedure, there are risks related to administering cycloplegic drops, and the reproducibility rates are low $(4,5)$.

Handheld autorefractors and photorefractometers capable of making non-cycloplegic measurements from a certain

How to cite this article: Kara C, Petricli IS. Accuracy of Photorefraction and Wavefront-Based Autorefraction in Children Under 3 Years of Age. Beyoglu Eye J 202I; 6(I): 54-6I.

Address for correspondence: Caner Kara, MD. Etlik Zubeyde Hanim Kadin Sagligi Egitim ve Arastirma Hastanesi Goz Hastaliklari Klinigi, Ankara, Turkey

Phone: +90 5317918540 E-mail: canerkara@hotmail.com

Submitted Date: December 04, 2020 Accepted Date: February 06, 2021 Available Online Date: February 13, 2021

${ }^{\circ}$ Copyright 2021 by Beyoglu Eye Training and Research Hospital - Available online at www.beyoglueye.com OPEN ACCESS This work is licensed under a Creative Commons Attribution-NonCommercial 4.0 International License. 
distance are available as another option to detect refractive errors in childhood $(6,7)$. These devices have the benefit of quicker and easier measurements and requiring minimal cooperation. Higher repeatability rates and the ability to reduce accommodation by making relatively distanced measurements are also advantages (8).

It is not entirely clear whether or not these devices can be an adequate alternative to cycloplegic retinoscopy. Previous studies have reported varying degrees of difference between cycloplegic retinoscopic measurements and non-cycloplegic measurements obtained with these devices, depending on the age of the study population and the devices studied (9-19).

Most studies assessing the accuracy of these devices have included a wide pediatric age range. There are few studies of patients under the age of 3 , which is the group for whom the devices might be most beneficial (20). To the best of our knowledge, no study has yet specifically assessed the 2 devices examined in this study in patients under 3 years of age. The objective was to evaluate the accuracy of photorefraction and wavefront-based autorefraction with these tools in this age group.

\section{Methods}

This cross-sectional study was performed on children under the age of 3 who were presented at an ophthalmology outpatient clinic for a routine eye examination between May 2017 and September 2017. The research was conducted in compliance with the ethical principles of the Helsinki Declaration and approved by the institutional review board. The Institutional Review Board of Etlik Zübeyde Hanim Women's Health Education and Research Hospital (Date: 05.06.2020, Number: 08).

Spot Vision Screener (Welch Allyn Inc., Skaneateles Falls, NY, USA) was used for photorefraction and SureSight Vision Screener (Welch Allyn Inc., Skaneateles Falls, NY, USA) device was used for autorefraction.

Spot Vision is a portable, handheld, infrared photoscreener that automatically and simultaneously analyzes the pupillary red reflex in both eyes and provides information about non-cycloplegic refraction values, interpupillary distance, pupil diameter, and any deviation. It can take measurements in as little as 2 seconds from a distance of I meter. Random visual patterns on the front of the device and an audible sound emitted attract the child's attention. The measurement screen displays a distance warning to facilitate use, as well as useful information about ambient lighting when the pupil size is inadequate. The screen reports whether the subject is too far or too close and displays a spinning circle and the child's face during data acquisition. The device is capable of making spherical measurements between -7.50 and 7.50 D, and cylindrical measurements between -3.00 and $3.00 \mathrm{D}$. Additionally, it can measure deviation up to $20^{\circ}$ in superior, temporal, and nasal directions, as well as measuring pupil size ranging from $4 \mathrm{~mm}$ to $9 \mathrm{~mm}$.

The SureSight autorefractor is based on a Shack-Hartmann wavefront analyzer. The device takes monocular measurements from an approximate range of $35 \mathrm{~cm}$. Attention-grabbing sounds ensure the child's focus and inform the user about the range of measurement. The device can make spherical measurements at a range of $-4.50 \mathrm{D}$ to 5.50 $D$ and cylindrical measurements at a range of 0 D to -4.00 D. Measurements outside of that range are displayed as 9.99 or -9.99. The device can make measurements in 2 different modes: child mode and adult mode. In child mode, the device takes into account children's accommodation characteristics and automatically adds $2.00 \mathrm{D}$ to spherical values.

Patients with a history of ocular surgery, eccentric fixation, nystagmus, or opacity affecting the optical axis were excluded from the study, since the goal was to assess the accuracy of the devices. Patients with refractive errors that were outside the measurement range of the devices were also excluded. Each patient was examined in the following order:

I. Measurement with Spot Vision (Since a longer distance can be used, it was performed first so as not to scare the child.)

2. Measurement with SureSight (child mode)

3. Evaluation of fixation and eye movements and assessment of accommodation with dynamic retinoscopy

4. A preliminary examination, including the Hirschberg test, cover/uncover test, and alternate cover test

5. Induction of cycloplegia (administration of tropicamide $0.5 \%$ and phenylephrine $2.5 \%$ for infants younger than 6 months of age, and cyclopentolate $0.5 \%$ and phenylephrine $2.5 \%$ for older infants) The second stage of the study was performed after a 45-minute wait

6. Re-measurement with Spot Vision

7. Re-measurement with SureSight (adult mode)

8. Retinoscopy with handheld corrective lenses (Heine Beta 200; Heine Optotechnik GmbH \& Co., Gilching, Germany)

9. Fundus examination with an indirect ophthalmoscope (Heine Video Omega 2C; Heine Optotechnik GmbH \& Co., Gilching, Germany)

All of the measurements were performed by the first author of the manuscript, an ophthalmologist with more than 2 years of experience with the study devices, and the retinoscopy was randomly performed by both authors. All of the assessments were performed before noon and in the same room.

Spherical, cylindrical, and spherical equivalent (SE) values were evaluated. Since traditional analysis of the astigmatic component is problematic, the mean spherical, cylindrical, and axis components were converted to vectorial values using the following formula reported by Thibos (2I): 
Spherical equivalent diopter $(D)=$ sphere $(D)+[$ cylin$\operatorname{der}(D) / 2]$,

Jackson cross-cylinder at axis $0^{\circ}(\mathrm{J} 0)=(-[$ cylinder $(\mathrm{D}) / 2]$ $\cos [2 \times$ axis $])$, and

Jackson cross-cylinder at axis $45^{\circ}(\mathrm{J} 45)=(-$ cylinder (D)/2] $\sin [2 \times$ axis]).

In this conversion, $\mathrm{S}$ denotes the spherical value, $\mathrm{C}$ denotes the negative cylindrical value, and axis denotes the angular value in terms of radians. Three optical components are determined: the spherical equivalent value and 2 Jackson cross-cylinder values. $J 0$ represents the powers at $90^{\circ}$ and $180^{\circ}$, with negative values indicating against-the-rule astigmatism and positive values indicating with-the-rule astigmatism. J45 values denote oblique astigmatism. Positive J45 values define $135^{\circ}$ and negative values define an astigmatic component of $45^{\circ}$.

As the measured values yielded a high correlation between the right and left eyes, the assessments were performed using the right-eye measurements. Continuous variables were expressed as the mean $\pm \mathrm{SD}$ and the categorical variables as numbers and percentages. The normality of data distribution was tested with the Kolmogorov-Smirnov test. The agreement between non-cycloplegic and cycloplegic retinoscopic measurements was tested with Bland-Altman analysis. A 95\% limits of agreement was determined using $1.96 \times$ SD. Correlations between the differences in measurements and refraction values were tested with Pearson or Spearman correlation analysis, depending on the data distribution. A P value of $<0.05$ was considered statistically significant.

\section{Results}

A total of 339 children were recruited into the study at baseline. It was observed that Spot Vision did not obtain a refractive result in 8 patients (2.4\% of patients) and SureSight did not yield a refractive result in 26 patients ( $7.7 \%$ of patients) due to high refractive errors beyond the instruments' dioptric range (out of range). These patients were excluded from the research, and the final study group consisted of 305 children.

Of the 305 patients, 155 were girls and 150 were boys. The median age was 11 months and the mean age was $15 \pm 10$ months (range: 3-36 months).

All of the children had demonstrated fixation and following a near object. In dynamic retinoscopy, anisometropia was suspected in 7 patients and high hyperopia in 10 patients, and the findings were confirmed with cycloplegic retinoscopy. Strabismus was detected in 3 patients.

The mean refractive value obtained with both devices and cycloplegic retinoscopy are shown in Table I. Comparisons of measurements are displayed in Table 2.

\section{Comparison of the non-cycloplegic device measure- ments with cycloplegic retinoscopy results}

The non-cycloplegic SE values obtained with both devices were significantly lower than the SE values measured with cycloplegic retinoscopy $(\mathrm{p}<0.00 \mathrm{I}$, paired t-test). That difference was greater with Spot Vision than with SureSight (-I.10 D vs. $-0.63 \mathrm{D}$ ). The $95 \%$ limits of agreement of SE values was -3.50 to I.30 D for Spot Vision and -3.30 to 2.10 D for SureSight. The Bland-Altman graphics showing the agreement between the non-cycloplegic device measurements and cycloplegic retinoscopy are provided in Figure $\mathrm{I}$.

The difference in SE values between the non-cycloplegic device measurements and the cycloplegic retinoscopy measurements was less than $0.50 \mathrm{D}$ in $14.1 \%$ of patients when using Spot Vision, and $28.9 \%$ with SureSight. The corresponding rate for a $1.00 \mathrm{D}$ difference was $50.9 \%$ for Spot Vision and $59.3 \%$ for SureSight. The frequency distribution of differences between SE values obtained with both devices with and without cycloplegia and SE values obtained with cycloplegic retinoscopy are shown in Figure 2.

Table I. The mean refractive values obtained with the devices studied and cycloplegic retinoscopy

\begin{tabular}{|c|c|c|c|}
\hline & $\begin{array}{c}\text { SE (D) } \\
\text { Mean士SD (Range) }\end{array}$ & $\begin{array}{c}\text { J0 (D) } \\
\text { Mean士SD (Range) }\end{array}$ & $\begin{array}{c}\text { J45 (D) } \\
\text { Mean士SD (Range) }\end{array}$ \\
\hline \multicolumn{4}{|l|}{ Spot Vision } \\
\hline Non-cycloplegic & $0.43 \pm 0.75(-1.75$ to 3.50$)$ & $0.49 \pm 0.48(-0.62$ to 2.24$)$ & $0.02 \pm 0.25(-0.87$ to 0.95$)$ \\
\hline Cycloplegic & $1.80 \pm 1.25(-1.37$ to 5.38$)$ & $0.53 \pm 0.42(-0.72$ to 1.94$)$ & $0.00 \pm 0.25(-0.80$ to 0.80$)$ \\
\hline \multicolumn{4}{|l|}{ SureSight } \\
\hline Cycloplegic & $1.55 \pm 1.4(-1.87$ to 5.00$)$ & $0.42 \pm 0.4 \mathrm{I}(-0.70$ to $\mathrm{I} .50)$ & $0.04 \pm 0.19(-0.86$ to 1.06$)$ \\
\hline \multicolumn{4}{|l|}{ Retinoscopy } \\
\hline Cycloplegic & $1.53 \pm 1.34(-2.00$ to 5.25$)$ & $0.44 \pm 0.4(-0.5$ to 1.75$)$ & $0.00 \pm 0.09(-0.98$ to 0.87$)$ \\
\hline
\end{tabular}

D: Diopter; SE: Spherical equivalent; J0: Jackson cross-cylinder power at axis $90^{\circ}$ and $180^{\circ}$; J45: Jackson cross-cylinder power at axis $45^{\circ}$ and $135^{\circ}$. 
Table 2. Comparisons between the measurements obtained with the devices evaluated and cycloplegic retinoscopy

\begin{tabular}{|c|c|c|c|c|c|}
\hline & & & $\begin{array}{c}\text { SE (D) } \\
\text { Mean (95\% LOA) }\end{array}$ & $\begin{array}{c}J 0(D) \\
\text { Mean (95\% LOA) }\end{array}$ & $\begin{array}{c}J 45(D) \\
\text { Mean (95\% LOA) }\end{array}$ \\
\hline $\begin{array}{l}\text { Spot Vision } \\
\text { Non-cycloplegic }\end{array}$ & vs. & $\begin{array}{l}\text { Retinoscopy } \\
\text { Cycloplegic }\end{array}$ & $-1.10(-3.30 \text { to } 1.30)^{*}$ & $0.05(-0.63 \text { to } 0.72)^{* *}$ & $0.02(-0.48$ to $0.5 \mathrm{I})$ \\
\hline $\begin{array}{l}\text { Spot Vision } \\
\text { Cycloplegic }\end{array}$ & vs. & $\begin{array}{l}\text { Retinoscopy } \\
\text { Cycloplegic }\end{array}$ & $0.27(-0.94 \text { to } 1.47)^{*}$ & $0.09(-0.56 \text { to } 0.74)^{*}$ & $0.00(-0.5 \mathrm{I}$ to 0.50$)$ \\
\hline $\begin{array}{l}\text { SureSight } \\
\text { Non-cycloplegic }\end{array}$ & vs. & $\begin{array}{l}\text { Retinoscopy } \\
\text { Cycloplegic }\end{array}$ & $-0.63(-3.30 \text { to } 2.10)^{*}$ & $0.06(-0.47 \text { to } 0.59)^{*}$ & $0.04(-0.36 \text { to } 0.44)^{*}$ \\
\hline $\begin{array}{l}\text { SureSight } \\
\text { Cycloplegic }\end{array}$ & vs. & $\begin{array}{l}\text { Retinoscopy } \\
\text { Cycloplegic }\end{array}$ & $0.01(-1.10$ to 1.10$)$ & $-0.03(-0.48$ to 0.43$)$ & $0.03(-0.32 \text { to } 0.38)^{*}$ \\
\hline
\end{tabular}

*: significant at $\mathrm{p}<0.00 \mathrm{I}$,**: significant at $\mathrm{p}<0.05$; D: Diopter; SE: Spherical equivalent, J0: Jackson cross-cylinder power at axis $90^{\circ}$ and $180^{\circ}$; 345 : Jackson crosscylinder power at axis $45^{\circ}$ and $135^{\circ}$; LOA: Limit of agreement.

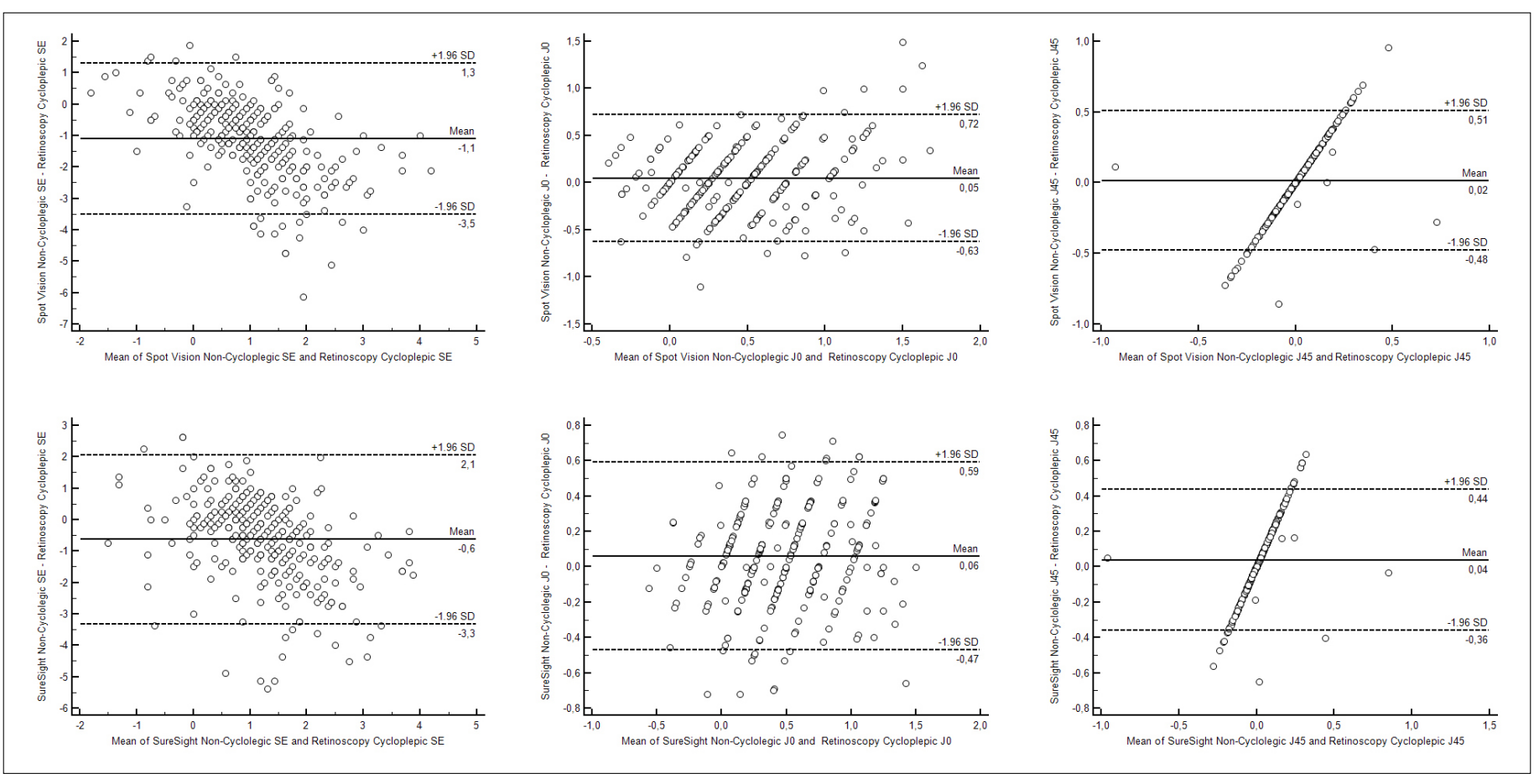

Figure I. Bland-Altman plots showing agreement between non-cycloplegic device measurements and cycloplegic retinoscopy measurements for spherical equivalent (SE) and Jackson cross-cylinder power values (J0 and J45).

There was a significant negative correlation between SE values obtained with cycloplegic retinoscopy and the difference in SE values obtained with both devices without cycloplegia and cycloplegic retinoscopy ( $p<0.00 \mathrm{I}$, Pearson test). Accordingly, that difference increased with an increasing degree of hyperopia. This correlation is represented graphically in Figure 3.

The non-cycloplegic J0 and J45 values with both devices were higher than the cycloplegic retinoscopy $\mathrm{J} 0$ and $\mathrm{J} 45 \mathrm{val}-$ ues. That difference was similar for $\mathrm{J0}$ values with both devices, whereas SureSight produced slightly higher J45 values than Spot Vision.

\section{Comparison of cycloplegic measurements with cy- cloplegic retinoscopy results}

A comparison of cycloplegic device measurements with cycloplegic retinoscopy results revealed that SureSight provided SE measurements similar to those seen with retinoscopy $(p=0.66$, paired $t$-test). Spot Vision's cycloplegic measurements, on the other hand, were significantly higher than those of cycloplegic retinoscopy $(p<0.00 \mathrm{I}$, paired t-test) The agreement between both cycloplegic devices measurements and the cycloplegic retinoscopy is shown in Figure 4.

The proportion of patients with a SE difference of less 


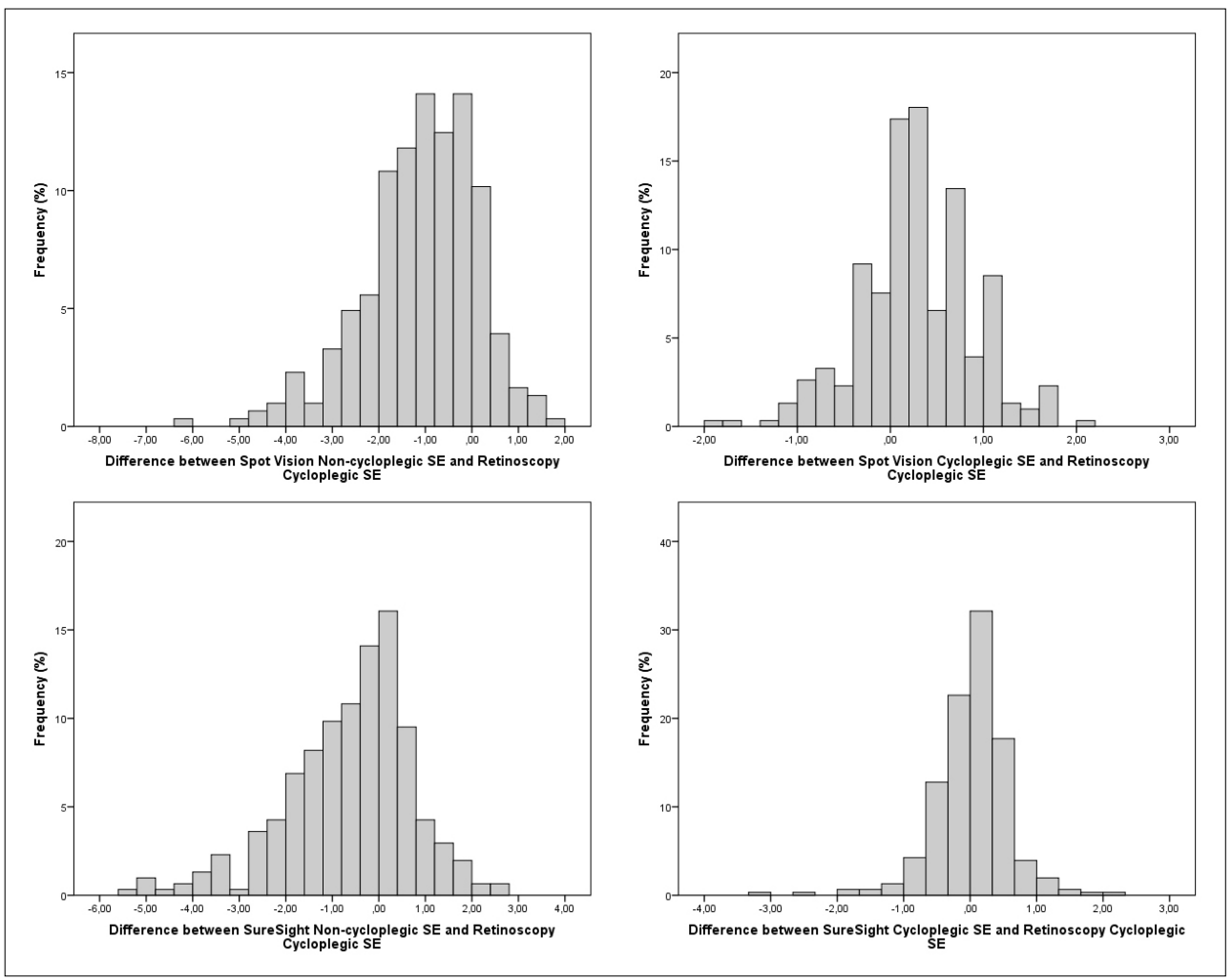

Figure 2. Frequency distribution of differences in the spherical equivalent (SE) values obtained with both devices with and without cycloplegia and the mean SE values obtained with cycloplegic retinoscopy.

than $0.50 \mathrm{D}$ between the cycloplegic device measurements and cycloplegic retinoscopy measurements was $60 \%$ for Spot Vision and $\mathbf{8 3 . 7 \%}$ for SureSight. The corresponding rate for a difference $<1.00 \mathrm{D}$ was $\mathbf{8 7 . 5 \%}$ for Spot Vision and $96.7 \%$ for SureSight (Fig. 2)

In terms of $\mathrm{J} 0$ and $\mathrm{J} 45$ values, Spot Vision yielded higher J0 values but similar $\mathrm{J} 45$ values to cycloplegia than cycloplegic retinoscopy. In contrast, SureSight yielded lower J0 values but higher $J 45$ values than cycloplegia. Although a statistical- ly significant difference was found between cycloplegic Spot Vision J0 values and cycloplegic SureSight J45 values, that difference did not exceed 0.10 D for any measurement.

\section{Discussion}

In the present study, 2 handheld measurement devices using different principles were compared in a patient population that was under 3 years of age and found that both devices underestimated SE values when compared with cycloplegic
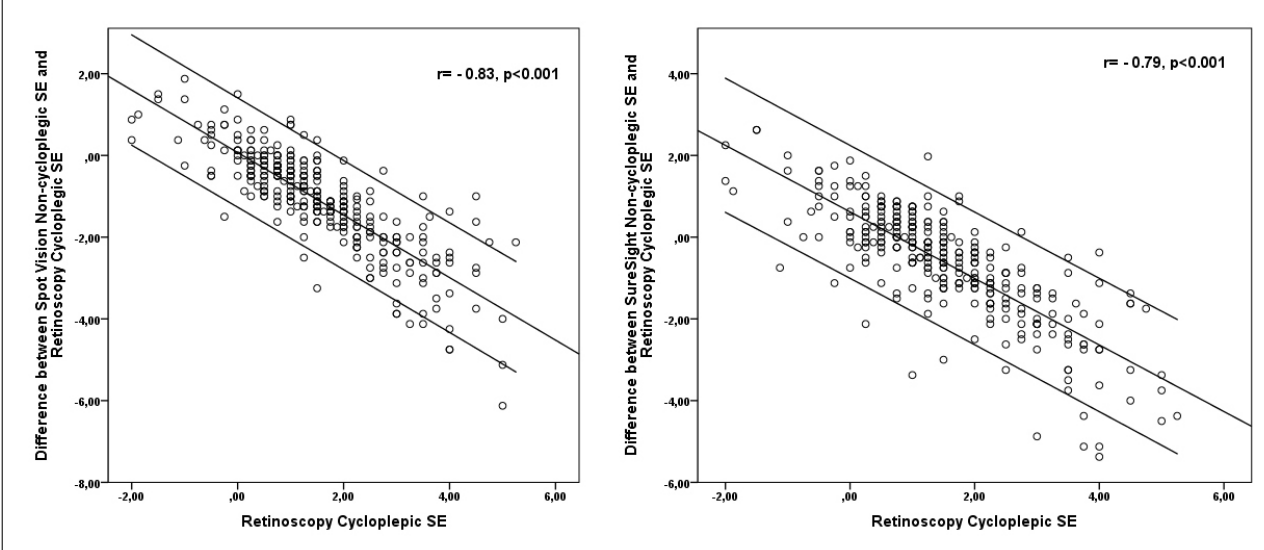

Figure 3. Correlation between the mean spherical equivalent (SE) values obtained with cycloplegic retinoscopy and the difference in SE values obtained with both devices without cycloplegia and cycloplegic retinoscopy. 


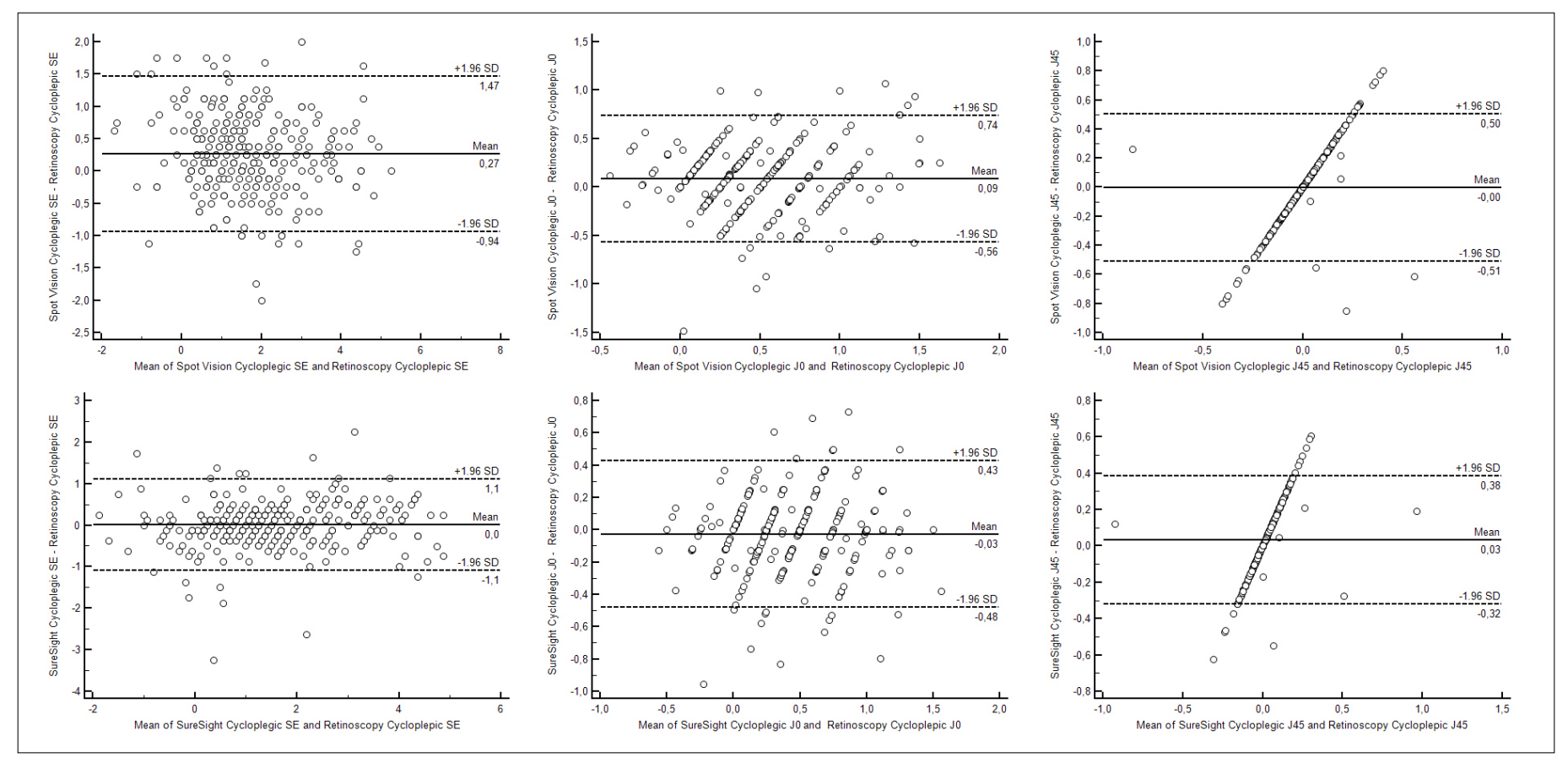

Figure 4. Bland-Altman plots showing the agreement between cycloplegic measurements of spherical equivalent (SE) and Jackson cross-cylinder power values (J0 and J45) obtained with both devices and cycloplegic retinoscopy.

retinoscopy results. This finding became even more prominent as the hyperopia degree increased.

Accommodation has a significant effect on refractive evaluations. In close-field autorefractors, the phenomenon of instrument myopia can be largely eliminated using the fogging method in adults, however, the same does not apply to children (22). It has been reported that fogging was not sufficient and instrument myopia due to accommodation persisted among children in close-field autorefractor measurements (23). It has been also shown that the open-field autorefractors do not adequately solve accommodation in children (24). Although relocating the focus of these devices at a distance was able to eliminate instrumental myopia, fixation myopia still led to lower SE values (17). The lower non-cycloplegic values found in this study can be explained by fixation myopia.

Most research published to date has reported similar results to those determined in this study. Among studies performed with Spot Vision, De Jesus et al. (13) reported a difference of $0.66 \mathrm{D}$ compared with cycloplegic retinoscopy in a group of patients aged 7 to 50 years. Mu et al. (14) reported a difference of $0.49 \mathrm{D}$ in 155 patients aged 4 to 7 years. Sharma et al. (18) observed a difference as low as 0.06 $D$ in 219 children aged 0.5 to 5 years. Qian et al. (16) found a difference of $0.17 \mathrm{D}$ in 113 children aged 4 to 6 years. In the present study, we noted that the non-cycloplegic values obtained by Spot Vision were lower by I. I0 D than those recorded with cycloplegic retinoscopy. This result is a bit high- er than those reported by the studies mentioned. A plausible explanation could be greater accommodation capacity in the age group studied.

The SureSight is a handheld autorefractor based on wavefront technology measures refractive error monocularly and has a child mode for use on children which adds a correction value of $2.0 \mathrm{D}$ in order to compensate accommodation. Among studies that have examined its accuracy, Stelle et al. (19) found a difference of $0.30 \mathrm{D}$ between non-cycloplegic SureSight measurements and cycloplegic retinoscopy measurements in their comparison of Retinomax (Right Manufacturing Co. Ltd., Tokyo, Japan) and SureSight in 35 children aged 3 to 5 years,. Another study by Schimitzek et al. (25) reported a difference of $1.59 \mathrm{D}$ with cycloplegic retinoscopy among $5 \mathrm{I}$ patients aged 2 to 76 years. This study found a difference of $0.63 \mathrm{D}$, which is greater than that observed by Stelle et al. (19). This may be due to the age group of the enrolled patients. Interestingly, the difference reported by Schimitzek et al. (25) was significantly greater than that of both our study and Stelle et al. (19), despite the older age of the study group. The major reason seems to be that child mode was not used for non-cycloplegic measurements in that study.

Accuracy analysis of the cycloplegic measurements of both devices indicated that the cycloplegic measurements were more closely related to those of cycloplegic retinoscopy than the non-cycloplegic measurements, in terms of SE values. Although cycloplegic measurements with SureSight 
also yielded very close results, the cycloplegic measurements with Spot Vision were higher by about $0.25 \mathrm{D}$. Yilmaz Kiyak et al. (9) found that cycloplegic measurements with the PlusOptix S04 (PlusOptix GmbH, Nuremberg, Germany), another photoscreener that uses the same principle, were higher by $1.06 \mathrm{D}$. Similarly, Yassa et al. (26) reported that cycloplegic measurements with PlusOptix were higher by 0.78 D. Özdemir et al. (27) found that photorefraction with cycloplegia led to overestimation of SE and spherical power. Schimitzek et al. (17), on the other hand, reported that PlusOptix made cycloplegic measurements that were $0.12 \mathrm{D}$ lower in an adult patient group (median age: 43 years). The higher SE values found in our research using Spot Vision support 3 of these studies; the results reported by Schimitzek et al. (17) may have been different due to an adult group. Such a difference with cycloplegia is likely to have resulted from the effect of pupil dilation (28). A study examining the cycloplegic accuracy of SureSight reported only a very slight difference $(0.01 \mathrm{D})$ compared with cycloplegic measurements (25). Our results were consistent.

Our assessment of the astigmatic values of Spot Vision and SureSight devices revealed that both measured non-cycloplegic J0 values a bit higher without cycloplegia, and with cycloplegia they were higher with Spot Vision and less with SureSight. Similarly, previous studies have reported slightly higher non-cycloplegic $J 0$ values, with the difference ranging between $0.01 \mathrm{D}$ and $0.16 \mathrm{D}(12-14,16,19,29)$. Although Schimitzek et al. (25) also observed less of a difference between the cycloplegic J0 measurements with SureSight, to our knowledge, an increase in the $\mathrm{J0}$ values with cycloplegia with Spot Vision has not previously been observed. Even though we believe that this results from exaggerated peripheral aberrations due to pupil dilation and the measurement principles of both devices, studies with larger series may be helpful to clarify the effect of cycloplegia on astigmatic measurements in both devices. In terms of oblique astigmatic values, there was a marked agreement in the results of both devices, particularly with Spot Vision, compared with cycloplegic retinoscopy.

Our results and those of other studies of these devices have found a series of differences, and it may be meaningful to consider a $95 \%$ limits of agreement values to determine reliability for clinical use. Our findings indicated that the $95 \%$ limit of agreement of the difference between Spot Vision's cycloplegic and non-cycloplegic measurements was between $-3.00 \mathrm{D}$ and I.30 D, while the corresponding range for SureSight was $-3.30 \mathrm{D}$ to $2.10 \mathrm{D}$. The difference in the measurements of both devices comprises a range of $>4.00 \mathrm{D}$. This seems to be too large for clinical use. As for the cycloplegic measurements, the range was reduced to $2.50 \mathrm{D}$ for Spot Vision and 2.00 D for SureSight. The rate of a $\pm 0.50 \mathrm{D}$ differ- ence rose from $14.1 \%$ to $60 \%$ for cycloplegic measurements with Spot Vision, and from $28.9 \%$ to $83.7 \%$ for cycloplegic measurements with SureSight.

Many studies, including our own research, have observed different levels of accuracy, and while some were at broadly clinically acceptable levels, these devices were primarily designed to detect amblyogenic risk factors in the preverbal age group. A complete ophthalmic examination, including visual acuity measurement of each eye using an acuity wall chart remains the gold standard in the diagnosis of amblyopia. In addition, the limited measurement ranges of both devices may restrict the use of these devices in the pediatric age group, especially in strabismic and anisometropic cases. In this study, the rate of failure to obtain a refractive value was $2.4 \%$ with Spot Vision and $7.7 \%$ with SureSight. The study population of this study consisted of children who were to undergo a routine control; the failure rate would be higher if the study group consisted of patients with a high prevalence of refractive errors. Additionally, in the presence of strabismus, it might be more difficult for photoscreeners to obtain refractive data and might therefore have low rates of accuracy due to the working principle of analyzing images of the red reflex (10).

Including only children younger than 36 months of age, in whom the use of these devices might be most beneficial, is a strength of the present study. However, there are some limitations. For example, only patients who were presented for a routine check-up were enrolled, rather than patients with high-degree refractive errors who required refractive correction. Another limitation is that even though retinoscopic measurements were randomly performed by 2 observers, they were not fully blind to the device measurements.

In conclusion, neither photoscreeners nor handheld, wavefront-based refractometer devices have adequate accuracy for non-cycloplegic clinical use due to the high accommodative capacity in this age group. For cycloplegic assessment, although wavefront-based assessment yielded similar results to those of cycloplegic retinoscopy, the question of whether it could be a suitable alternative to cycloplegic retinoscopy for clinical use should be addressed in large-scale studies.

\section{Disclosures}

Ethics Committee Approval: The Institutional Review Board of Etlik Zübeyde Hanim Women's Health Education and Research Hospital (Date:05.06.2020, Number:08).

Peer-review: Externally peer-reviewed.

Conflict of Interest: None declared.

Authorship Contributions: Involved in design and conduct of the study (CK, ISP); preparation and review of the study (CK, ISP); data collection (CK, ISP); and statistical analysis (CK). 


\section{References}

I. Webber AL, Wood J. Amblyopia: prevalence, natural history, func- tional effects and treatment. Clin Exp Optom 2005;88:365-75. [CrossRef]

2. Kirk VG, Clausen MM, Armitage MD, Arnold RW. Preverbal photoscreening for amblyogenic factors and outcomes in amblyopia treatment: early objective screening and visual acuities. Arch Ophthalmol 2008; 126:489-92. [CrossRef]

3. Pascual M, Huang J, Maguire MG, Kulp MT, Quinn GE, Ciner E, et al; Vision In Preschoolers (VIP) Study Group. Risk factors for amblyopia in the vision in preschoolers study. Ophthalmology 2014;121:622-9.el. [CrossRef]

4. Harvey EM, Miller JM, Dobson V, Tyszko R, Davis AL. Measurement of refractive error in Native American preschoolers: validity and reproducibility of autorefraction. Optom Vis Sci 2000;77:|40-9. [CrossRef]

5. Zadnik K, Mutti DO, Adams AJ. The repeatability of measurement of the ocular components. Invest Ophthalmol Vis Sci 1992;33:2325-33.

6. Ottar WL, Scott WE, Holgado SI. Photoscreening for amblyogenic factors. J Pediatr Ophthalmol Strabismus 1995;32:289-95.

7. Harvey EM, Miller JM, Wagner LK, Dobson V. Reproducibility and accuracy of measurements with a hand held autorefractor in children. Br J Ophthalmol 1997;81:94I-8. [CrossRef]

8. Sanchez I, Ortiz-Toquero S, Martin R, de Juan V. Advantag-es, limitations, and diagnostic accuracy of photoscreeners in early detection of amblyopia: a review. Clin Ophthalmol (Auckland, NZ) 2016;10:1365-73. [CrossRef]

9. Ayse YK, Onder U, Suheyla K. Accuracy of Plusoptix S04 in children and teens. Can J Ophthalmol 20I I;46:153-7. [CrossRef]

10. Dahlmann-Noor AH, Comyn O, Kostakis V, Misra A, Gupta $\mathrm{N}$, Heath J, et al. Plusoptix Vision Screener: the accuracy and repeatability of refractive measurements using a new autore fractor. Br J Ophthalmol 2009;93:346-9. [CrossRef]

II. Demirci G, Arslan B, Özsütçü M, Eliaçık M, Gulkilik G. Comparison of photorefraction, autorefractometry and retinoscopy in children. Int Ophthalmol 20I4;34:739-46. [CrossRef]

12. Demirel S, Bilak Ş, Yuvacı I, Cumurcu T, Çolak C. Objective measurement of refractive errors: Comparison of plusoptix s08 with a standard autorefractometer. J Clin Exp Invest 2013;4:40-6.

13. de Jesus DL, Villela FF, Orlandin LF, Eiji FN, Dantas DO, Alves MR. Comparison between refraction measured by Spot Vision ScreeningTM and subjective clinical refractometry. Clinics (Sao Paulo) 2016;71:69-72. [CrossRef]

14. Mu Y, Bi H, Ekure E, Ding G, Wei N, Hua N, et al. Performance of spot photoscreener in detecting amblyopia risk factors in Chinese pre-school and school age children attending an eye clinic. PLoS One 2016; I I:e014956I. [CrossRef]

15. Peterseim MM, Papa CE, Wilson ME, Cheeseman EW, Wolf BJ, Davidson JD, et al. Photoscreeners in the pediatric eye office: compared testability and refractions on high-risk children. Am J
Ophthalmol 2014; 158:932-8. [CrossRef]

16. Qian X, Li Y, Ding G, Li J, Lv H, Hua N, et al. Compared performance of Spot and SW800 photoscreeners on Chinese children. Br J Ophthalmol 2019;103:517-22. [CrossRef]

17. Schimitzek T, Lagrèze WA. Accuracy of a new photo-refractometer in young and adult patients. Graefes Arch Clin Exp Ophthalmol 2005;243:637-45. [CrossRef]

18. Sharma M, Ganesh S, Tibrewal S, Sabharwal S, Sachdeva N, Adil $M$, et al. Accuracy of noncycloplegic photorefraction using Spot photoscreener in detecting amblyopia risk factors in preschool children in an Indian eye clinic. Indian J Ophthalmol 2020;68:504-9. [CrossRef]

19. Steele G, Ireland D, Block S. Cycloplegic autorefraction results in pre-school children using the Nikon Retinomax Plus and the Welch Allyn SureSight. Optom Vis Sci 2003;80:573-7. [CrossRef]

20. Moghaddam AA, Kargozar A, Zarei-Ghanavati M, Najjaran M, Nozari V, Shakeri MT. Screening for amblyopia risk factors in pre-verbal children using the Plusoptix photoscreener: a cross-sectional population-based study. $\mathrm{Br} \mathrm{J}$ Ophthalmol 2012;96:83-6. [CrossRef]

2I. Thibos LN, Wheeler W, Horner D. Power vectors: an application of Fourier analysis to the description and statistical analysis of refractive error. Optom Vis Sci 1997;74:367-75. [CrossRef]

22. Salvesen S, Køhler M. Automated refraction. A compara-tive study of automated refraction with the Nidek AR-I000 autorefractor and retinoscopy. Acta Ophthalmol (Copenh) 1991;69:342-6. [CrossRef]

23. Zhao J, Mao J, Luo R, Li F, Pokharel GP, Ellwein LB. Accuracy of noncycloplegic autorefraction in school-age children in China. Optom Vis Sci 2004;81:49-55. [CrossRef]

24. Kara C, Petriçli i S. Inability of open-field autorefraction to eliminate accommodation in preschoolers. J Pediatr Ophthalmol Strabismus 2017;54:3 I I-18. [CrossRef]

25. Schimitzek T, Wesemann W. Clinical evaluation of refraction using a handheld wavefront autorefractor in young and adult patients. J Cataract Refract Surg 2002;28:1655-66. [CrossRef]

26. Yassa ET, Unlu C. Comparison of autorefraction and photorefraction with and without cycloplegia using $1 \%$ tropicamide in preschool children. J Ophthalmol 2019;2019:1487013. [CrossRef]

27. Ozdemir O, Özen Tunay Z, Petriçli IS, Ergintürk Acar D, Erol MK. Comparison of non-cycloplegic photorefraction, cycloplegic photorefraction and cycloplegic retinoscopy in children. Int J Ophthalmol 2015;8:|28-31.

28. Roorda A, Campbell MC, Bobier WR. Slope-based eccentric photorefraction: theoretical analysis of different light source configurations and effects of ocular aberrations. J Opt Soc Am A Opt Image Sci Vis 1997; 14:2547-56. [CrossRef]

29. Dahlmann-Noor AH, Vrotsou K, Kostakis V, Brown J, Heath J, Iron A, et al. Vision screening in children by Plusoptix Vision Screener compared with gold-standard orthoptic assessment. $\mathrm{Br}$ J Ophthalmol 2009;93:342-5. [CrossRef] 